\title{
Analisis Pendapatan Usahatani Pisang Klutuk di Desa Puhu Kecamatan Payangan Kabupaten Gianyar
}

\author{
JESICA AGUSTIN, I GUSTI AGUNG AYU AMBARAWATI, \\ WAYAN BUDIASA
}

Program Studi Agribisnis, Fakultas Pertanian, Universitas Udayana

Jalan PB. Sudirman Denpasar Bali 80323

Email : agustinjesica@gmail.com

annie_ambarawati@unud.ac.id

\section{Abstract \\ Income Analysis of Klutuk Bananas at Puhu Village Payangan District Gianyar Regency}

This study aims to determine costs used, revenue and income of klutuk banana farming. The location of the research was determined purposively at Puhu Village, Payangan District, Gianyar Regency. The population in this study was klutuk banana farmers at Puhu Village, Payangan District, Gianyar Regency. The sampling technique used was purposive sampling method. Samples in this study were 55 respondents of farmers determined by using Slovin method. This research uses descriptive quantitative and qualitative to calculate income of klutuk banana cultivation at Puhu Village. The results of this study show that average farm income received by farmers was Rp 3,503,207 in the first year and in the second year at amount Rp 4,401,317. Technical obstacles experienced by farmers on klutuk banana farming at Puhu Village were the existence of green grasshopper and strong wind. Hindrance from the economic point of view was price fluctuations between wet and dry seasons.

Keywords: klutuk banana leaf, income, obstacles

\section{Pendahuluan}

\subsection{Latar Belakang}

Peranan sektor pertanian sebagai sumber penghasil bahan kebutuhan pokok, menyediakan lapangan kerja, memberikan sumbangan terhadap pendapatan nasional yang tinggi dan memberikan devisa kepada negara, juga dapat menjadi basis dalam mengembangkan kegiatan ekonomi pedesaan melalui pengembangan usaha berbasis pertanian (Antara, 2009). Tingginya sumbangan sektor pertanian terhadap pendapatan nasional dapat dilihat dari kontribusi sektor pertanian. Sektor pertanian yang memberikan sumbangan terhadap pendapatan nasional yang tinggi, dapat dilihat dari kontribusi sektor pertanian terhadap Produk Domestik Bruto (PDB) pada tahun 2010 s.d 2014 mendapatkan peringkat ketiga sebesar 13\% dari rata-ratasumbangan PDB Indonesia setelah sektor industri pengolahan dan sektor perdagangan. Hal ini 
menunjukkan bahwa sektor pertanian memberikan kontribusi yang cukup besar terhadap pertumbuhan ekonomi nasional (BPS Nasional, 2015).

Secara luas lapangan usaha pada sektor pertanian dikelompokkan ke dalam lima sub sektor, salah satunya adalah sub sektor hortikultura. Kontribusi sub sektor hortikultura dalam pembangunan pertanian terus meningkat, tercermin dalam beberapa indikator pertumbuhan ekonomi seperti: PDB, nilai ekspor, penyerapan tenaga kerja, nilai tukar petani, peningkatan gizi, dan perbaikan estetika lingkungan. Buah pisang merupakan salah satu komoditi hortikultura yang memiliki sumbangan PDB tertinggi dan memiliki peningkatan yang cukup signifikan (BPS Provinsi Bali, 2015). Produk hortikultura ini memiliki berbagai keunggulan dibandingkan dengan komoditas produk hortikultura lainnya antara lain permintaan pasar yang tinggi, hampir seluruh bagiannya bisa dimanfaatkan, varietas yang beragam, dapat dikonsumsi sebagai buah segar dan olahan serta keuntungan yang diperoleh dalam usahatani pisang cukup besar. Tanaman pisang dibagi menjadi empat jenis yaitu pisang yang dimakan buahnya tanpa dimasak, pisang yang dimakan setelah buahnya dimasak, pisang berbiji yang di Indonesia dimanfaatkan daunnya, dan pisang yang diambil seratnya (Sudarma, 2013).

Pisang klutuk yang tergolong pisang berbiji yang buahnya tidak bisa dimakan, akan tetapi daunnya yang memiliki nilai pasaran tinggi. Daun pisang memiliki permintaan pasar yang sangat tinggi di Provinsi Bali, khususnya Kota Denpasar. Biasanya digunakan sebagai pembungkus berbagai macam makanan tradisional khas Bali, salah satunya adalah nasi jinggo (Vinantya, 2015). Terdapat dua daerah yang mengusahatanikan pisang klutuk di Provinsi Bali yaitu Kabupaten Jembrana dan Kabupaten Gianyar. Daun pisang klutuk yang dihasilkan pada kedua daerah tersebut memiliki kelebihan dan kekurangannya masing - masing. Daun pisang yang dihasilkan dari Kabupaten Jembrana memiliki beberapa kekurangan seperti, warna daun hijau pucat dan lebih cepat menguning, serta memiliki kelebihan yaitu jumlah lepit daun pisang lebih banyak jika dibandingkan dengan daun pisang yang dihasilkan dari Kabupaten Gianyar yaitu sebanyak 12 lepit dalam satu ikat. Daun pisang yang dihasilkan dari Kabupaten Gianyar memiliki beberapa kelebihan seperti, warna hijau segar dan tidak cepat menguning serta memiliki kekurangan pada jumlah lepitnya yaitu hanya sebanyak 10 lepit dalam satu ikat.

Desa Puhu merupakan desa yang mengembangkan usahatani tanaman pisang klutuk yang terletak di Kecamatan Payangan, Kabupaten Gianyar. Awalnya beberapa tahun terakhir penerimaan hasil usahatani padi mengalami penurunan yang menyebabkan para petani di Desa Puhu beralih fungsi lahan tanaman pisang klutuk yang hanya dijadikan sebagai tanaman pembatas (Renyep, Kepala Desa Puhu, Komunikasi Personal, 2013). Luas tanamnya untuk saat ini melebihi dari luar lahan bukan sawah dan penerimaan hasil produksi dapat membantu meningkatkan pendapatan petani di Desa Puhu. Melihat kondisi petani di Desa Puhu yang ingin berinvestasi usahatani pisang klutuk yang tinggi maka menarik untuk dikaji.

\subsection{Rumusan Masalah}

Berdasarkan latar belakang di atas dapat dirumuskan beberapa permasalahan sebagai berikut:

1. Berapakah besar pendapatan usahatani pisang klutuk bagi petani di Desa Puhu, Kecamatan Payangan, Kabupaten Gianyar.

2. Hambatan apakah yang dihadapi petani dalam berusahatani pisang klutuk di Desa Puhu, Kecamatan Payangan, Kabupaten Gianyar. 


\subsection{Tujuan Penelitian}

Berdasarkan latar belakang dan rumusan masalah yang telah diuraikan, maka tujuan dari penelitian ini adalah untuk:

1. Mengetahui pendapatan usahatani pisang klutuk di Desa Puhu, Kecamatan Payangan, Kabupaten Gianyar.

2. Mengetahui hambatan yang dihadapi petani dalam berusahatani pisang klutuk di Desa Puhu, Kecamatan Payangan, Kabupaten Gianyar.

\section{Metode Penelitian}

\subsection{Lokasi dan Waktu Penelitian}

Penelitian ini telah dilakukan di Desa Puhu, Kecamatan Payangan, Kabupaten Gianyar. Pengambilan data dilaksanakan pada bulan Juni hingga Agustus 2017. Pemilihan lokasi penelitian dilakukan dengan sengaja menggunakan metode purposive sampling dengan berdasarkan pertimbangan sebagai berikut; (1) Desa Puhu merupakan salah satu sentra penghasil daun pisang klutuk di Provinsi Bali, (2) Desa Puhu merupakan daerah pengembangan usahatani pisang klutuk di Kecamatan Payangan, Kabupaten Gianyar, dan (3) Produksi daun pisang klutuk dengan permintaan yang paling banyak di pasaran, khususnya Kota Denpasar.

\subsection{Populasi dan Sampel}

Populasi dalam penelitian ini adalah petani yang menanam pisang klutuk di tegalan/kebun pisang yang berjumlah 120 orang. Penarikan sampel dalam penelitian ini menggunakan purposive sampling dimana pengambilan anggota sampel dengan cara mengambil subjek yaitu petani pisang klutuk di Desa Puhu yang sudah memiliki pengalaman berusahatani pisang klutuk minimal tiga tahun. Rumus Slovin digunakan untuk menentukan jumlah sampel yang mewakili jumlah populasi. Maka didapatkan 55 orang petani pisang klutuk sebagai sampel yang mewakili jumlah populasi dalam penelitian ini.

\subsection{Data dan Metode Pengumpulan Data \\ 2.3.1 Jenis dan sumber data}

Jenis data yang digunakan dalam penelitian ini adalah data kuantitatif dan data kualitatif. Data kuantitatif merupakan data yang berupa angka-angka yang dapat dihitung yakni biaya-biaya yang dikeluarkan selama proses produksi mulai dari masa tanam sampai masa panen. Data kualitatif merupakan data yang berupa kata-kata, kalimat, dan gambar yang digunakan meliputi identitas petani, lokasi penelitian, dan hambatan - hambatan usahatani pisang klutuk. Sumber data dalam penelitian ini yaitu data primer dan data sekunder. Data primer dalam penelitian ini diperoleh dari observasi dan wawancara langsung menggunakan daftar pertanyaan kepada petani pisang klutuk mengenai kegiatan dan biaya-biaya yang dikeluarkan berusahatani pisang klutuk. Data sekunder merupakan data yang diperoleh secara tidak langsung dari sumbernya, misalnya dari sumber - sumber pustaka dan catatan serta dokumen - dokumen dari Balai Penyuluhan Pertanian Kecamatan Payangan, Badan Pusat Statistik (BPS) Provinsi Bali, Dinas Pertanian Provinsi Bali, Perpustakaan Provinsi Bali, buku-buku penunjang dan jurnal - jurnal yang berhubungan dengan penelitian kegiatan usahatani. 


\subsubsection{Metode pengumpulan data}

Metode pengumpulan data yang digunakan dalam penelitian ini adalah wawancara (interview) dengan menggunakan kuisioner, observasi dengan melakukan pengamatan dengan cermat secara langsung mengenai masalah yang diteliti yaitu pada kegiatan usahatani pisang klutuk di Desa Puhu, dan berbagai studi pustaka yang ada yang berhubungan dengan penelitian.

\subsection{Variabel Penelitian dan Pengukuran}

Variabel penelitian yang digunakan dalam analisis ini yaitu variabel pendapatan usahatani dengan indikator pertama yang digunakan adalah total penerimaan usahatani pisang klutuk yang menggunakan parameter jumlah produksi dan harga jual daun pisang. Indikator kedua yang digunakan adalah total biaya usahatani pisang klutuk yang meliputi seluruh kegiatan produksi usahatani pisang klutuk dengan parameter biaya input usahatani pisang klutuk.

\subsection{Metode Analisis Data}

Metode analisis data yang digunakan dalam penelitian ini ada dua macam, yaitu (1) analisis data kuantitatif, digunakan untuk mengetahui besarnya penerimaan usahatani, biaya produksi, dan pendapatan usahatani pisang klutuk selama proses produksi, dan (2) analisis data kualitatif, digunakan untuk mengetahui kendala-kendala dalam berusahatani pisang klutuk.

\subsection{Analisis Usahatani Pisang Klutuk}

\subsubsection{Penerimaan usahatani pisang klutuk}

Penerimaan usahatani pisang klutuk dapat dihitung dengan cara harga jual daun pisang klutuk dikali dengan jumlah produksi dalam jangka waktu tahun pertama dan tahun kedua dengan rumus sebagai berikut:

$$
T R=P x Q
$$

Keterangan:

$$
\begin{array}{ll}
\mathrm{TR} & =\text { Total penerimaan/Total revenue }(\mathrm{Rp} / \mathrm{luas} \text { garapan/th) } \\
\mathrm{P} & =\text { Harga produk/Price }(\mathrm{Rp} / \mathrm{ikat}) \\
\mathrm{Q} & =\text { Jumlah produk/Quantity (ikat) }
\end{array}
$$

\subsubsection{Biaya usahatani pisang klutuk}

\subsubsection{Biaya tetap}

Biaya tetap terdiri atas biaya investasi dan biaya penyusutan alat-alat pertanian. Biaya investasi ini meliputi biaya sarana produksi yang dikeluarkan dalam kegiatan usahatani pisang klutuk dari awal penanaman sampai panen produksi daun pisang klutuk. Biaya investasi dalam penelitian ini merupakan pembelian bibit yang dikeluarkan dimana pembebanan investasi dilakukan setiap tahun mengingat usahatani pisang klutuk hanya pada awal saja membeli bibit dan tahun berikutnya ada anakan yang terus berkembang sampai tanaman berumur lima tahun. Biaya investasi bibit dibagi menjadi lima sesuai dengan umur ekonomis tanaman. Biaya tetap lainnya meliputi biaya pajak yang dibayar setiap tahun, biaya sarana upacara selama berusahatani tanaman pisang klutuk, dan biaya penyusutan alat-alat pertanian seperti cangkul dan sabit. Besarnya biaya penyusutan alat-alat pertanian yang digunakan untuk 
usahatani pisang klutuk dihitung dengan menggunakan metode garis lurus. Metode ini digunakan dengan asumsi bahwa alat-alat pertanian yang digunakan dalam usahatani pisang klutuk menyusut dalam besaran yang sama dalam setiap tahun.

\subsubsection{Biaya variabel}

Biaya variabel dihitung dari biaya pupuk, obat-obatan dan tenaga kerja yang digunakan dalam berusahatani. Biaya pupuk terdiri dari biaya pupuk kandang dan biaya pupuk urea yang digunakan dalam berusahatani. Tenaga kerja yang digunakan dalam usahatani pisang klutuk terdiri dari pria dan wanita. Semua biaya-biaya di atas dihitung dalam jangka waktu produksi tahun pertama dan tahun kedua. Biaya total dihitung dengan rumus:

$$
\mathrm{TC}=\mathrm{TFC}+\mathrm{TVC}
$$

Keterangan :

$\mathrm{TC}=$ Total biaya /Total Cost (Rp/th/luas garapan)

$\mathrm{TFC}=$ Total biaya tetap/Total fixed cost $(\mathrm{Rp} / \mathrm{th} / \mathrm{luas}$ garapan $)$

$\mathrm{TVC}=$ Total biaya tidak tetap/Total variable cost $(\mathrm{Rp} / \mathrm{th} /$ luas garapan $)$

\subsubsection{Pendapatan usahatani}

Pendapatan usahatani pisang klutuk dapat dihitung dengan cara mengurangi total penerimaan petani dikurangi dengan total biaya selama berusahatani dengan rumus sebagai berikut:

$$
\Pi=\mathrm{TR}-\mathrm{TC}
$$

Keterangan:

$\Pi \quad=$ Pendapatan $(\mathrm{Rp} / \mathrm{luas}$ garapan/th)

$\mathrm{TR}=$ Penerimaan total/Total revenue $(\mathrm{Rp} / \mathrm{th})$

$\mathrm{TC}=$ Biaya total/Total cost $(\mathrm{Rp} / \mathrm{th})$

\subsubsection{Kemampuan menghasilkan keuntungan}

Efisiensi merupakan perbandingan output dan input berhubungan dengan tercapainya output maksimum dengan sejumlah input, artinya jika rasio output input besar, maka efisiensi dikatakan semakin tinggi (Seokartawi, 2003). Metode yang digunakan untuk mengetahui efisiensi usahatani pisang klutuk digunakan rumus:

$$
\mathrm{R} / \mathrm{C} \text { Ratio }=\frac{\text { Total Penerimaan... }}{\text { Total Biaya }}
$$

Dari rumus diatas dapat diketahui kriteria dari R/C Ratio sebagai berikut :

- Apabila R/C Ratio > 1 maka usahatani pisang klutuk dikatakan mengalami keuntungan.

- $\quad$ Apabila R/C Ratio = 1 maka usahatani pisang klutuk berada dalam kondisi BEP (Impas).

- Apabila R/C Ratio < 1 maka usahatani pisang klutuk dikatakan mengalami kerugian.

Profit rate digunakan untuk menghitung layak atau tidaknya usahatani tersebut dikembangkan. Profit rate dapat dihitung menggunakan rumus profitabilitas dengan rumus:

$$
\text { Profitabilitas }=\frac{\pi}{\mathrm{TC}} \times 100 \%
$$


Keterangan:

$\Pi \quad=$ Pendapatan $(\mathrm{Rp} / \mathrm{luas}$ garapan/th $)$

$\mathrm{TC}=$ Biaya total/Total cost $(\mathrm{Rp} / \mathrm{th})$

Profitabilitas (profit rate) dapat ditentukan berdasarkan tingkat inflasi (inflation rate) di daerah setempat, dengan kriteria sebagai berikut:

a. $\quad$ Profit Rate > Inflation Rate, maka usahatani pisang klutuk menguntungkan atau profitable yaitu usahatani pisang klutuk tersebut layak untuk dilanjutkan.

b. Profit Rate < Inflation Rate, maka usahatani pisang klutuk tidak menguntungkan atau non profitable yaitu usahatani pisang klutuk tersebut layak untuk dilanjutkan.

\section{Hasil dan Pembahasan}

\subsection{Karakteristik Responden}

Berdasarkan hasil penelitian, rata-rata umur responden adalah 43,93 tahun dengan kisaran umur antara 27 sampai dengan 66 tahun, dengan tingkat pendidikan formal paling tinggi adalah tamat SMP sebesar 38,18 \% dan yang paling rendah adalah tidak bersekolah sebanyak 3,64 \%. Karakteristik berdasarkan jenis kelamin dapat diketahui bahwa rata-rata berjenis kelamin perempuan dan petani responden rata-rata memiliki pengalaman dalam berusahatani pisang klutuk selama 4,35 tahun dengan kisaran antara tiga tahun sampai dengan enam tahun. Hal ini dapat disimpulkan bahwa para petani di Desa Puhu memiliki pengalaman yang cukup dalam berusahatani pisang klutuk. Pengalaman bertani akan mempengaruhi tingkat keterampilan para petani dalam mengelola usahataninya. Semakin lama berpengalaman, maka semakin luas wawasan para petani terhadap usahatani yang dilakukannya.

\subsection{Analisis Usahatani Pisang Klutuk di Desa Puhu Kecamatan Payangan Kabupaten Gianyar}

\subsubsection{Produksi dan penerimaan usahatani pisang klutuk}

Usahatani pisang klutuk berbeda dengan usahatani pisang lainnya, karena yang diambil hasil produksinya adalah daun pisangnya saja. Rata-rata panen produksi daun pisang adalah sebanyak tujuh kali dalam setahun. Sistem produksi tanaman pisang klutuk pada tahun pertama dimulai pada bulan keenam sampai bulan ke 12. Pada tahun kedua, pada umumnya petani menunggu \pm dua - tiga bulan selanjutnya agar memperoleh daun pisang lebih banyak. Berdasarkan hasil penelitian pada tahun pertama jumlah pohon sebanyak 730 pohon pisang rata-rata mampu menghasilkan produksi jumlah daun pisang sebanyak 544 ikat per luas garapan. Pada tahun kedua jumlah pohon yang dihasilkan yaitu sebanyak 749 pohon pisang yang rata-rata mampu menghasilkan produksi jumlah daun pisang sebanyak 646 ikat per luas garapan. Terjadinya peningkatan sebesar $18,75 \%$ pada tahun kedua karena jumlah pohon mengalami pertumbuhan anakan sebanyak 50 s.d 100 pohon. Jumlah tersebut didapat pada rata-rata luas garapan petani sebesar 0,30 ha dan rata-rata harga jual daun pisang sebesar Rp 8.805/ikat. Maka diperoleh penerimaan sebesar Rp 4.789.920/luas garapan pada tahun pertama dan sebesar Rp. 5.688.030/luas garapan pada tahun kedua.

\subsubsection{Biaya usahatani pisang klutuk}

\subsubsection{Biaya tetap}

Biaya tetap pada tahun pertama dan tahun kedua yang dikeluarkan petani pisang klutuk sebesar Rp 703.369/luas garapan dengan rata-rata luas lahan sebesar 0,30 ha. 
Tabel 1.

Biaya Tetap Usahatani Pisang Klutuk di Desa Puhu Kecamatan Payangan Kabupaten Gianyar

\begin{tabular}{|c|c|c|c|c|c|}
\hline \multirow{2}{*}{ No } & \multirow{2}{*}{ Uraian } & \multicolumn{2}{|c|}{ Tahun I } & \multicolumn{2}{|c|}{ Tahun II } \\
\hline & & Jumlah (Rp) & $(\%)$ & Jumlah (Rp) & $(\%)$ \\
\hline 1 & Biaya bibit & 416.504 & 59,22 & 416.504 & 59,22 \\
\hline 2 & Biaya penyusutan & 104.492 & 14,86 & 104.492 & 14,86 \\
\hline 3 & Biaya pajak & 7.373 & 1,05 & 7.373 & 1,05 \\
\hline 4 & Biaya sarana upacara & 175.000 & 24,88 & 175.000 & 24,88 \\
\hline & Total & 703.369 & 100,00 & 703.369 & 100,00 \\
\hline
\end{tabular}

Sumber: Diolah dari data primer.

Berdasarkan Tabel 1 biaya tetap pada tahun pertama dan tahun kedua yang dikeluarkan petani pisang klutuk sebesar Rp 703.369/luas garapan (0,30 ha). Biaya tersebut terbagi kedalam biaya bibit yang dikeluarkan petani pisang klutuk sebesar Rp $416.504(59,22 \%)$. Nilai ini diperoleh dari total biaya bibit sebesar Rp 2.082 .521 dibagi sesuai dengan umur ekonomis tanaman pisang. Kemudian biaya penyusutan alat-alat pertanian yang digunakan seperti sabit dan cangkul sebesar Rp 104.492 (14,86\%), biaya pajak yang dibayar setiap tahun sebesar Rp 7.373 (1,05\%), dan biaya sarana upacara selama berusahatani pisang klutuk sebesar Rp 175.000 (24,88\%).

\subsubsection{Biaya variabel}

Tabel 2.

Biaya Variabel Usahatani Pisang Klutuk di Desa Puhu Kecamatan Payangan Kabupaten Gianyar

\begin{tabular}{ccrrrr}
\hline \multirow{2}{*}{ No } & \multirow{2}{*}{ Uraian } & \multicolumn{2}{c}{ Tahun I } & \multicolumn{2}{c}{ Tahun II } \\
\cline { 3 - 6 } & & Jumlah (Rp) & \multicolumn{1}{c}{$(\%)$} & Jumlah $(\mathrm{Rp})$ & \multicolumn{1}{c}{$(\%)$} \\
\hline \multirow{2}{*}{1} & Biaya pupuk kandang & 5.175 & 0,89 & 5.175 & 0,89 \\
2 & Biaya pupuk urea & 82.036 & 14,06 & 82.036 & 14,06 \\
3 & Biaya tenaga kerja & 496.132 & 85,05 & 496.132 & 85,05 \\
\hline \multicolumn{2}{c}{ Total } & 583.343 & 100,00 & 583.343 & 100,00 \\
\hline
\end{tabular}

Sumber: Diolah dari data primer

Berdasarkan Tabel 2 biaya variabel pada tahun pertama dan tahun kedua yang dikeluarkan petani pisang klutuk sama sebesar $R p$ 583.343/luas garapan (0,30 ha). Biaya tersebut terbagi kedalam biaya pupuk kandang sebesar Rp 5.175 (0,89\%), biaya pupuk urea sebesar Rp 82.036 (14,06\%), dan biaya tenaga kerja sebesar Rp 496.132 $(85,05 \%)$.

\subsubsection{Biaya total}

Tabel 3.

Biaya Total Usahatani Pisang Klutuk di Desa Puhu Kecamatan Payangan Kabupaten Gianyar

\begin{tabular}{clrr}
\hline No & \multicolumn{1}{c}{ Uraian } & \multicolumn{1}{c}{ Tahun I } & \multicolumn{1}{c}{ Tahun II } \\
\hline 1 & Biaya tetap & 703.369 & 703.369 \\
2 & Biaya variabel & 583.343 & 583.343 \\
\hline 3 & Biaya total usahatani & 1.286 .713 & 1.286 .713 \\
\hline
\end{tabular}

Sumber: Diolah dari data primer 
Berdasarkan Tabel 3 biaya total dalam usahatani pisang klutuk yaitu keseluruhan jumlah biaya produksi yang dikeluarkan. Semua biaya-biaya di atas dihitung dalam jangka waktu produksi tahun pertama dan tahun kedua. Biaya total dihitung dengan menjumlahkan biaya tetap dan biaya variabel. Maka didapat total biaya yang dikeluarkan petani pisang klutuk di Desa Puhu yaitu sebesar Rp 1.286.713/luas garapan.

\subsubsection{Pendapatan petani pisang klutuk}

Pendapatan diperoleh dari selisih antara penerimaan usahatani dengan total biaya produksi yang digunakan. Pada penelitian ini diperoleh pendapatan petani pisang klutuk pada tahun pertama sebesar Rp 3.503.207 untuk rata-rata luas lahan sebesar 0,30 ha dan tahun kedua hasil pendapatan yang diperoleh sebesar Rp 4.401.317 juga untuk rata-rata luas lahan sebesar 0,30 ha. Usahatani pisang klutuk terjadi peningkatan sebesar 25,64\% dari tahun pertama ke tahun kedua dimana tanaman sudah menghasilkan secara penuh.

Tabel 4.

Pendapatan Usahatani Pisang Klutuk di Desa Puhu Kecamatan Payangan Kabupaten Gianyar

\begin{tabular}{clcc}
\hline \multirow{2}{*}{ No } & \multicolumn{1}{|}{ Uraian } & Tahun I & Tahun II \\
\cline { 3 - 4 } & & Jumlah $(\mathrm{Rp})$ & Jumlah $(\mathrm{Rp})$ \\
\hline 1 & Penerimaan Usahatani & $4.789,920$ & $5.688,030$ \\
2 & Biaya Usahatani & 1.286 .713 & 1.286 .713 \\
\hline 3 & Pendapatan Usahatani & 3.503 .207 & 4.401 .317 \\
\hline 4 & RC & 3,72 & 4,42 \\
\hline 5 & Profitabilitas & 2,72 & 3,42 \\
\hline \multicolumn{2}{l}{ Sumber $:$ Diolah dari data primer }
\end{tabular}

Berdasarkan Tabel 4 nilai R/C ratio pada usahatani pisang klutuk di Desa Puhu tahun pertama sebesar 3,72. Hal ini berarti bahwa setiap $\mathrm{Rp} 1.00$ biaya yang diinvestasikan usahatani pisang klutuk akan memberikan penerimaan sebesar Rp 3,72. Nilai R/C ratio pada tahun kedua usahatani pisang klutuk sebesar 4,42, ini berarti bahwa setiap Rp 1.00 biaya yang diinvestasikan usahatani pisang klutuk akan memberikan penerimaan sebesar Rp 4,42. Hal ini memberi indikasi bahwa usahatani pisang klutuk di Desa Puhu mulai dari tahun pertama sudah menguntungkan dan selanjutnya pada tahun kedua terjadi peningkatan keuntungan. Selain dapat dikatakan menguntungkan, perlu juga dilihat apakah usahatani pisang klutuk tersebut layak untuk dikembangkan. Layak atau tidaknya usahatani dikembangkan dapat dihitung dengan profit rate (profitabilitas). Nilai profitabilitas usahatani pisang klutuk pada Tabel 4 terlihat tahun pertama sebesar 2,72 dan 3,42 pada tahun kedua. Profitabilitas dapat ditentukan berdasarkan tingkat inflasi. Nilai inflasi yang digunakan yaitu nilai inflasi di Kota Denpasar sebesar 0,48 pada tahun 2016. Hasil tersebut dapat disimpulkan bahwa usahatani pisang klutuk menguntungkan petani di Desa Puhu dan layak untuk dikembangkan. Nilai profit rate > inflation rate maka usahatani pisang klutuk menguntungkan atau profitable yaitu usahatani pisang klutuk tersebut layak untuk dilanjutkan.

\subsection{Hambatan-hambatan Berusahatani Pisang Klutuk}

Hambatan yang dialami petani dalam usahatani pisang klutuk di Desa Puhu meliputi dua aspek, yaitu aspek teknis dan aspek ekonomi. Aspek teknis dalam penelitian ini mencakup gangguan hama dan penyakit serta terjainya angin kencang. Berdasarkan hasil penelitian diketahui sebanyak 15 petani responden $(27 \%)$ menyatakan 
usahataninya diserang oleh hama belalang. Hama belalang ini berpengaruh terhadap produksi daun pisang klutuk walaupun sangat kecil. Belum ada cara penanggulangan khusus yang dilakukan oleh petani untuk mengurangi dampak yang ditimbulkan hama belalang tersebut. Hal ini dikarenakan hama belalang yang menyerang tidak dalam jumlah banyak atau berkelompok, sehingga tidak terlalu berisiko kerugian. Hama belalang yang menyerang petani biasanya ditangkap dan dijadikan konsumsi petani tersebut. Hambatan teknis berupa angina kencang merupakan masalah utama yang harus dihadapi oleh seluruh petani pisang klutuk. Ketika musim hujan tiba yang disertai dengan angin kencang dapat menyebabkan kerusakan pada daun pisang seperti robek. Jika daun pisang mengalami kerusakan secara menyeluruh, hal ini akan menyebabkan kerugian terhadap petani tersebut. Pelanggan tidak mau membeli daun dengan kualitas rendah seperti daun robek. Pelanggan mengeluhkan daun pisang tersebut tidak dapat digunakan sebagaimana mestinya. Pelanggan yang pada umumnya menggunakan daun pisang klutuk adalah pedagang nasi jinggo dan pembuat sarana persembahyangan.

Hambatan pada aspek ekonomis yang dirasakan oleh petani mencakup adanya fluktuasi harga daun pisang. Menurut keterangan petani pisang klutuk, harga daun pisang klutuk pada musim hujan jauh lebih rendah dibandingkan dengan pada musim kemarau. Pada musim hujan harga daun pisang mencapai Rp 6.000 sedangkan pada musim kemarau harga daun mencapai Rp 25.000/ikat. Rendahnya harga daun pisang pada musim hujan disebabkan oleh kualitas daun yang kurang baik seperti ukuran daun lebih kecil dari biasanya dan robek sebagai akibat dari angina kencang. Sedangkan pada musim kemarau kualitas daunnya lebih bagus seperti warna daun tetap segar dan lebar.

\section{Simpulan dan Saran}

\subsection{Simpulan}

Usahatani pisang klutuk di Desa Puhu, Kecamatan Payangan, Kabupaten Gianyar menguntungkan petani. Hal ini dapat dilihat dari pendapatan petani pisang klutuk sebesar Rp 3.503.207 pada tahun pertama dan pada tahun kedua sebesar Rp 4.401.317 dengan rata-rata luas lahan sebesar $0,30 \mathrm{Ha}$. Usahatani pisang klutuk layak untuk dilanjutkan berdasarkan nilai $\mathrm{R} / \mathrm{C}$ ratio sebesar 3,72 dengan nilai profitabilitas sebesar 2,72 pada tahun pertama. Tahun kedua diperoleh nilai $\mathrm{R} / \mathrm{C}$ ratio 4,42 dengan nilai profitabilitas sebesar 3,42. Hambatan yang dialami oleh petani pisang klutuk di Desa

Puhu, Kecamatan Payangan, Kabupaten Gianyar selama berusahatani dapat dilihat dari segi teknis yaitu adanya hama belalang yang berpengaruh terhadap produksi daun pisang dan angin kencang yang dapat menyebabkan kerusakan pada daun pisang. Hambatan dari segi ekonomis yaitu adanya fluktuasi harga pada musim hujan dan musim kemarau.

\subsection{Saran}

Berdasarkan hasil pembahasan dan kesimpulan dapat disarankan kepada Dinas Tanaman dan Pangan Kabupaten Gianyar dan Penyuluh Pertanian Lapangan Kecamatan Payangan, untuk lebih mengintensifkan sosialisasi kepada petani pisang klutuk di Desa Puhu agar dapat meningkatkan wawasan dan dapat menyelesaikan masalah-masalah yang terjadi dalam berusahatani pisang klutuk, serta petani yang mengusahakan usahatani pisang klutuk dapat lebih melaksanakan teknis usahataninya. Usahatani ini menguntungkan dengan bimbingan dari penyuluh setempat. 


\section{Ucapan Terimakasih}

Ucapan terimakasih ini ditunjukan kepada petani pisang klutuk di Desa Puhu, yang telah membantu memberikan data dalam pelaksanaan penelitian hingga karya ilmiah ini dapat dipublikasikan di e-jurnal.

\section{Daftar Pustaka}

Antara, Made. 2015. Format Dan Substansi Proposal Penelitian Sosial Ekonomi. Program Studi Agribisnis Fakultas Pertanian Universitas Udayana. Denpasar.

BPS Nasional. 2015. Produk Domestik Bruto Atas Dasar Harga Konstan 2000 Menurut Lapangan Usaha (triliun rupiah), 2010-2014. www.bps.go.id. Diakses pada 20 Januari 2017.

BPS Provinsi Bali. 2015. Produksi Buah-Buahan di Indonesia Tahun 2014. Denpasar. Bali

BPS Kabupaten Gianyar. 2016. Statistik Daerah Kecamatan Payangan 2016. Gianyar. Bali.

Vinantya, Mikail Septian Adi. 2015. Nama Jenis Nasi di Indonesia: Tinjauan Struktur Frasa dan Dasar Penamaan. http://repository.usd.ac.id/1054/2/114114007 full.pdf. Diakses pada tanggal 30 November 2016

Renyep, Made. 2013. Profil Pembangunan Desa Puhu. Laporan Kegiatan. Gianyar Bali.

Soekartawi, Soeharjo, Jhon L. Dillon, dan J. Brian Hardaker. 1986. Ilmu Usahatani dan Penelitian Untuk Pengembangan Petani Kecil. Cetakan Ketiga. Universitas Indonesia.

Soekartawi. 2003. Teori Ekonomi Produksi dengan Pokok Bahasan Analisis Fungsi Cobb-Douglass. PT raja Grafindo Persada, Jakarta.

Sudarma, Made. 2013 . Penyakit Tanaman Pisang. Denpasar: Pelawa Sari.

Widyantara, Wayan. 2015. Bahan Ajar Manajemen Usahatani. Program Studi Agribisnis Fakultas Pertanian Universitas Udayana. Denpasar 